\title{
New hands at the helm
}

\author{
Roger A. Barker
}

Published online: 16 December 2011

(C) Springer-Verlag 2011

\section{Farewell to Gérard Said}

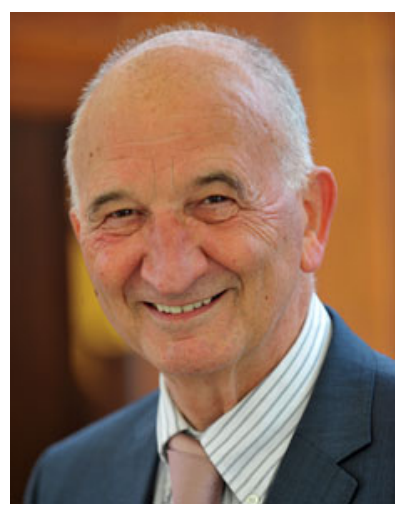

Gérard Said

It is with great regret that I have to say good-bye to my CoChief Editor Professor Gérard Said, who after 3 years has decided to step down. His successors, of whom there are two, are Michael Strupp and Massimo Filippi. Gérard took on this role with myself and Thomas Brandt back in January 2009 , and since then the journal has continued to grow in terms of the number of submissions it receives and its impact factor, in no small part because of Gérard's skills and his well-established and leading role in the European Neurological Society (ENS), to which the journal is linked.

\section{R. A. Barker ( $\square)$}

Cambridge Centre for Brain Repair, University of Cambridge,

The E.D. Adrian Building, Forvie Site, Robinson Way,

Cambridge CB2 2PY, UK

e-mail: rab46@cam.ac.uk
Gérard qualified in neurology from the medical school of the Salpêtrière back in 1971 and since then has become an international academic neurologist of great repute as well as being highly influential in many different areas of neurological practice and training, both nationally and internationally. Apart from being the Professor of Neurology and Chief of Service de Neurologie at the Centre Hospitalier Universitaire de Bicêtre, Université Paris-Sud from 1987 to 2007, he was also a co-founder of the ENS in 1986 with the late P.K. Thomas and Anita Harding. This new society was born out of a sense that there was nothing equivalent to the American Academy of Neurology in Europe. Gérard became the first Secretary General of the society until 2007 and has been instrumental in organising all of their yearly congresses. He became President of the ENS in 2010.

His main field of investigation has been in the area of peripheral neuropathies, where he has made many seminal contributions, and he is perhaps best known for his work on diabetic and vasculitic neuropathy. However, his work extends to many aspects of the peripheral nervous system, with influential work on infectious causes of peripheral nerve dysfunction such as HIV-associated neuropathies. This work has led not only to a better description and recognition of these conditions, but also to better investigation and treatment. This ability to master the whole spectrum of peripheral nerve disease has led to him taking an international role in this field of neurology. He has been Director of the Research Group on Neuromuscular Disorders of the World Federation of Neurology, and between 1998 and 2000 he was also President of the Peripheral Nerve Society (PNS).

During his 3 years at the helm of the Journal of Neurology Gérard has been instrumental in speeding up the review process, in bringing in new initiatives, and in 
ensuring that the standing of the journal continues to increase. He has shown great wisdom in all that he has done for the journal during this time, and the help and guidance he has shown to me and the Editorial Board as we move away from the paper form of the journal to more web-based electronic publication has been invaluable.

I would therefore like to thank him on behalf of all those that have worked with him at the journal over the past few years. We hope that he will continue to be actively involved in the review process, but he will no doubt be relieved to discover that on switching his e-mail on in the morning there is no longer an impressive list of pending "Editor assignments" to sort out!

\section{Welcome to Massimo Filippi and Michael Strupp}

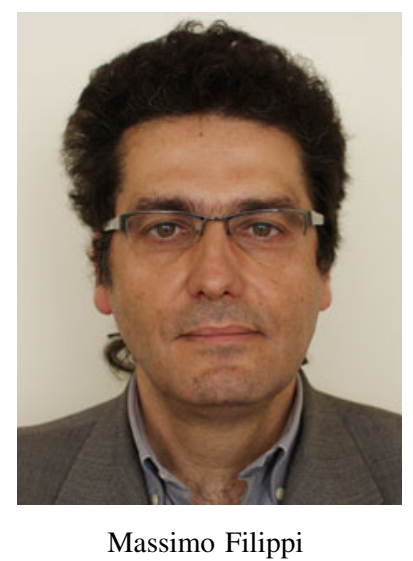

Massimo Filippi is currently Associate Professor of Neurology at Università Vita-Salute San Raffaele, Director of the interdepartmental research programme "BrainMap", and Director of the Neuroimaging Research Unit (NRU), Institute of Experimental Neurology, Division of Neuroscience, San Raffaele Scientific Institute, Milan, Italy. Dr. Filippi took his graduation in medicine in 1986 and his post-degree graduation in neurology in 1990. His research activity has focused on the use of MR-based technology to improve our understanding of how neurological diseases determine progressive accumulation of irreversible physical disability and cognitive impairment. As Director of the NRU, he coordinates the MRI acquisition and analysis of several large-scale international MRI-monitored trials of multiple sclerosis (MS).

Dr. Filippi is a member of various scientific societies and has been heavily involved with the ENS as a member of the Executive Committee, teaching course Director from 2009 to 2011, and Coordinator of the Neuroimaging Subcommittee.
$\mathrm{He}$ is a member of the editorial boards of many international scientific journals and acts as a reviewer on a regular basis for several others, and for many governmental organizations. $\mathrm{He}$ is author or co-author of more than 690 scientific papers published in peerreviewed journals ( $\mathrm{H}$ index: 76 ) and has edited several international volumes.

In 2001, Dr. Filippi was awarded the "Rita Levi Montalcini" Prize for his outstanding contributions to the application of MRI techniques in the study of MS.

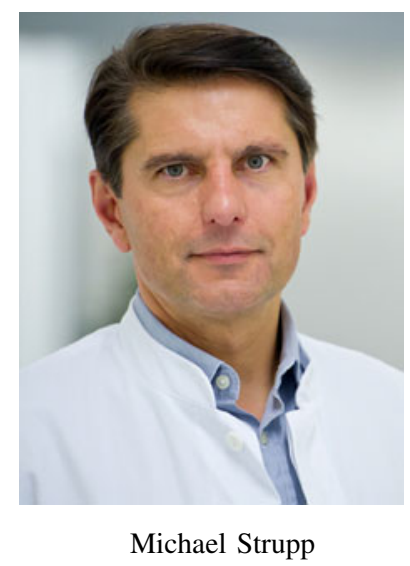

Michael Strupp is currently Professor of Neurology and Clinical Neurophysiology at the University of Munich as well as Deputy Speaker of the newly founded Integrated Center for Research and Treatment of Vertigo, Balance and Ocular Motor Disorders at the University of Munich $\left(\mathrm{IFB}^{\mathrm{LMU}}\right)$. He began his study of medicine at the Technical University of Aachen, where he also obtained his MD in the field of cardiophysiology. During his undergraduate studies, he spent half a year in Rochester, New York. After finishing medical school, he went to the University of Bern for his first residency in neurology. Following that, he spent 3 years working at the Department of Neurophysiology of the University of Munich, where he performed patch-clamp recordings with axons, muscle cells, glial cells and vestibular hair cells. His fields of research at that time involved the ischaemic resistance of axons from patients with diabetes and the pathophysiology of periodic paralyses. He subsequently did basic research at Baylor College, Houston and in Montpellier.

He then returned to Munich to join Thomas Brandt's Department of Neurology, having become a general neurologist with a wide exposure to many different subfields of neurology. As a specialist for vertigo, dizziness and eye movement disorders, he is at present engaged in the development and clinical evaluation of new therapeutic principles in this field. He has published articles not only on vestibular and oculomotor disorders, but also, for 
instance, on post-lumbar puncture syndrome and transient global amnesia.

Dr. Strupp has served as Assistant Editor of the Journal of Neurology for more than 10 years and has written the "Journal Club" articles for more than 12 years. He is currently also Editor-in-Chief of Frontiers in Neuro-otology. He has received many clinical and scientific awards, including a "best teacher" award from the German Neurological Society and an award of excellence from the Harvard-Munich Alliance. He has been a visiting professor at the University of Graz and the University of Prague. Michael Strupp is the author of more than 220 peerreviewed papers and four books on vertigo, dizziness and ocular motor disorders. 